\title{
SERONEGATIVE ANTIPHOSPHOLIPID SYNDROME
}

\author{
Manole Cojocaru ${ }^{1,2}$, Inimioara Mihaela Cojocaru ${ }^{3,4}$, Bogdan Chicos ${ }^{2}$ \\ ${ }^{1}$ Department of Physiology, Faculty of Medicine, ,, Titu Maiorescu“ University, Bucharest \\ ${ }^{2}$, ,Dr. Ion Stoia “ Clinical Center for Rheumatic Diseases, Bucharest \\ ${ }^{3}$ Department of Neurology, ,Carol Davila“ University of Medicine and Pharmacy, Bucharest \\ ${ }^{4}$, Prof. Gheorghe Marinescu“ Clinic of Neurology, Clinical Hospital Colentina, Bucharest
}

\begin{abstract}
Seronegative antiphospholipid syndrome (seronegative APS) has remained an enigma and the concept is controversial. A small group of APS patients remain persistently negative for routine assays of antiphospholipid (aPL) antibodies. The clinical features are well defined, and include the tendency to both arterial and venous thrombosis, to recurrent miscarriages, and to occasional thrombocytopenia. Patients with clinical manifestations highly suggestive of APS but persistently negative conventional aPLs are classified as having seronegative APS.
\end{abstract}

Keywords: seronegative antiphospholipid syndrome, negative antiphospholipid antibodies, clinical features

The antiphospholipid syndrome (APS) was described in 1983. The antiphospholipid syndrome is an autoimmune disease characterised by arterial and/or venous thromboses, recurrent abortions or foetal loss, and circulating antiphospholipid (aPL) antibodies (1-5).

However, as always in real clinical practice, there are often discrepancies between antibody levels and clinical disease expression. It is universally recognized that the routine screening tests - the anti-cardiolipin (aCL) antibodies and lupus anticoagulant, may miss some cases. A small group of APS patients remain persistently negative for routine assays of aPL (3-8).

Cases of aCL negativity but with positive anti$\beta_{2}$-glycoprotein 1 (anti- $\beta_{2}$-GP1) antibodies were exceptionally rare. According to the classification criteria, diagnosis of APS requires the combination of at least one clinical and one laboratory criterion (4-7).

As awareness increases, and the number of patients with APS grows, it comes as no surprise that seronegative APS provides the focus of day to day clinical discussion - the patient with migraine, stroke, several previous miscarriages, thrombocytopenia, and livedo reticularis, whose aPL tests are doggedly negative. Pathological livedo reticularis may therefore be a clinical marker of the seronegative APS (2-4).

Livedo reticularis was included in the original clinical description of the APS (Figure 1). Frances et al reported significant associations between pathological livedo reticularis and cerebral or ocular ischemic arterial events, seizures, heart valve abnormalities, hypertension and Raynaud's phenomenon in patients with APS. As with APS, livedo reticularis in the absence of aPL antibodies has been associated with pregnancy morbidity. Livedo reticularis shares a number of features with APS such as pregnancy loss, arterial thrombosis, heart valve abnormalities and seizures and indeed it is the most common cutaneous manifestation of APS. Livedoid vasculopathy is a rare condition which predominantly affects young women. It is characterized by intense painful purpuric maculae in the legs, ankles and feet, due to thrombosis of the small

Corresponding author:

Manole Cojocaru, 5 Thomas Masaryk St., Sector 2, Postal Code 020983 Bucharest

E-mail: mancojocaru@yahoo.com 


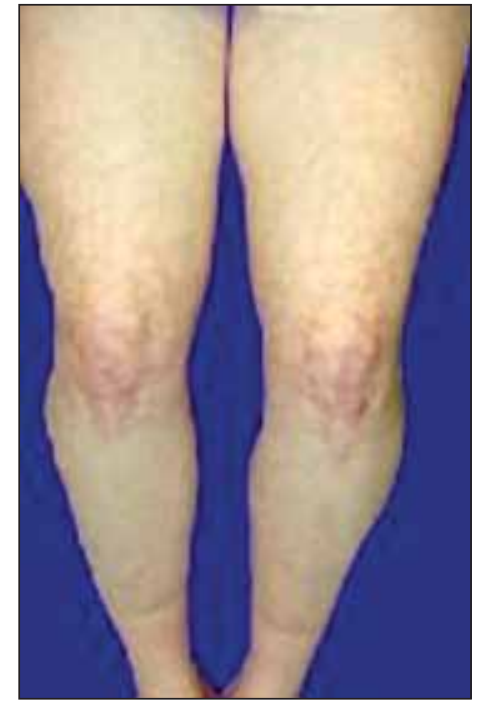

FIGURE 1.

Antiphospholipid syndrome. Livedo reticularis

and medium-sized dermal vessels, in the absence of vasculitis. Livedoid vasculopathy has been frequently associated with hypercoagulable states and APS. Tests for aPL antibodies were repeatedly negative (6-10).

In the clinical practice it is possible to find patients with clinical signs suggestive of APS, who are persistently negative for the laboratory criteria of APS, that is, aCL antibodies, anti- $\beta_{2}$-GP 1 antibodies and lupus anticoagulant. Therefore, it was proposed for these cases the term of seronegative APS (7-11).

The use of the term seronegative APS could be viewed as an inducement to clinical sloppiness (1217).

Three possible explanations for the existence of such seronegative cases have been proposed: either the diagnosis is wrong, or that previously positive
aPL tests have become negative, or, as seems most likely, the current range of tests is inadequate (815).

Antibodies may be directed for example against other phospholipids such as phosphatidylethanolamine, or against components of the protein $\mathrm{C}$ pathway or annexin $\mathrm{V}(18)$.

Is it possible that previously positive aPL titres become negative-either acutely by consumption during an acute thrombotic episode, or slowly, over time $(19,20)$.

As in rheumatoid arthritis and systemic lupus erythematosus, seronegativity also occurs in APS (20-23).

In conclusion, a syndrome in which antiphospholipid antibodies are not detected is called seronegative APS. The entity of seronegative APS, where patients have characteristic clinical manifestations of APS but lack conventional serological markers, has also been given consideration in classification criteria for APS. These findings suggest that in sera from patients with seronegative APS, antibodies may be detected using new antigenic targets or methodological approaches different from traditional techniques. Seronegative APS represents a mosaic, in which antibodies against different antigenic targets may be detected.

\section{Competing interests}

The authors declare that they have no competing interests.

\section{Author's contribution}

$\mathrm{IMC}$ and MMC equally contributed to this paper.

\section{REFERENCES}

1. Hughes G.R.V. Antiphospholipid syndrome (Hughes syndrome): 10 clinical topics. Lupus. 2010;19:343-6

2. Hughes G.R.V., Khamashta M.A. Seronegative antiphospholipid syndrome. Ann Rheum Dis. 2003; 62:1127

3. Roubey R.A.S., Roch B., Amengual O., Atsumi T., Khamashta M.A., Hughes G.R.V. Antiphospholipid antibody-negative syndromeother phospholipids. In Highes Syndrome. Antiphospholipid syndrome. Edited by Khamashta MA. London Springer 2000; 253-60

4. Wilson W.A., Gharavi A.E., Koike T., et al. International consensus statement on preliminary classification criteria for definite antiphospholipid syndrome. Arthritis and Rheumatism 1999; 42(7):1309-11

5. Miyakis S., Lockshin M.D., Atsumi T., et al. International consensus statement on an update of the classification criteria for definite antiphospholipid syndrome (APS). Journal of Thrombosis and Haemostasis. 2006; 4(2):295-306

6. Sangle S., Christodoulou C., Paul S., Hughes G.R., D'Cruz D.P. The point prevalence of an abnormal ankle-brachial index in

antiphospholipid antibody negative patients with livedo reticularis: a controlled study. Ann Rheum Dis. 2008; 67:276-7

7. Sangle S., D'Cruz D.P., Hughes G.R. Livedo reticularis and pregnancy morbidity in patients negative for antiphospholipid antibodies. Ann Rheum Dis. 2005;64:147-8

8. Conti F., Capozzi A., Truglia S., Lococo E., Longo A., Misasi R., Alessandri C., Valesini G., Sorice M. The Mosaic of "Seronegative" Antiphospholipid Syndrome. J Immunol Res. 2014; 2014:389601

9. Rovenský J. Seronegative Antiphospholipid Syndrome. Sine Syndromes in Rheumatology 2014;17-21

10. Frances C., Niang S., Laffitte E., Pelletier F., Costedoat N., Piette J.C. Dermatologic manifestations of the antiphospholipid syndrome: two hundred consecutive cases. Arthritis Rheum. 2005; 52:1785-93

11. Miyakis S., Lockshin M.D., Atsumi T., et al. International consensus statement on an update of the classification criteria for definite antiphospholipid syndrome (APS). Journal of Thrombosis and Haemostasis. 2006; 4(2):295-306 
12. Cervera R., Conti F., Doria A., laccarino L., Valesini G. Does seronegative antiphospholipid syndrome really exist? Autoimmun Rev. 2012;11(8):581-4

13. Jawad A.S. Seronegative antiphospholipid syndrome. Ann Rheum Dis 2004; 63(5):608

14. Wisløff F., Jacobsen E.M., Liestøl S. Laboratory diagnosis of the antiphospholipid syndrome. Thromb Res. 2002; 108(5-6):263-71.

15. Nayfe R., Uthman I,. Aoun J., Saad Aldin E., Merashli M., Khamashta M.A. Seronegative antiphospholipid syndrome. Rheumatology (Oxford) 2013; 52(8): 1358-67

16. Asherson R.A. The primary, secondary, catastrophic, and seronegative variants of the antiphospholipid syndrome: a personal history long in the making. Semin Thromb Hemost. 2008; 34(3):22735

17. Rodriguez-Garcia J.L., Bertolaccini M.L., Cuadrado M.J., et al. Clinical manifestations of antiphospholipid syndrome (APS) with and without antiphospholipid antibodies (the so-called "seronegative APS"). Ann Rheum Dis. 2012;71(2):242-4
18. Sanmarco M. Clinical significance of antiphosphatidylethanolamine antibodies in the so-called "seronegative antiphospholipid syndrome". Autoimmun Rev. 2009; 9:90-2

19. McCarty G.A. Seronegative APS (SNAPS) in 53 patients: seroconversion rate at 3,5 years. J Autoimmun. 2000; 15:0C35.

20. Miret C., Cervera R., Reverter J.C., et al. Antiphospholipid syndrome without antiphospholipid antibodies at the time of the thrombotic event: transient seronegative antiphospholipid syndrome? Clin Exp Rheumatol. 1997;15:541-4

21. Joseph J., Scopelitis E. Case report. Seronegative antiphospholipid syndrome associated with plasminogen activator inhibitor. Lupus. 1994; 3:201-3

22. Silveira L.H., Jara L.J., Espinoza L.R. Transient disappearance of serum antiphospholipid antibodies can also be due to prednisone therapy. Clin Exp Rheumatol. 1996; 14:217-26

23. Alessandri C., Conti F., Conigliaro P., Mancini R., Massaro L., Valesini G. Seronegative autoimmune diseases. Annals of the New York Academy of Sciences. 2009; 1173:52-9 